\title{
Modelling of droplet burning for rapeseed oil as liquid fuel
}

\author{
J. Parrilla ${ }^{1}$, C. Cortés ${ }^{2}$ \\ ${ }^{1} \mathrm{PhD}$ Student (University of Zaragoza) \\ C/ Los Diputados, 17, $3^{\circ} \mathrm{B}$ \\ 50004 Zaragoza (Spain) \\ Phone: +34 976 444777, Fax: +34 976 444777, email: javipar2000@hotmail.com \\ ${ }^{2}$ Department of Mechanical Engineering \\ Centro Politécnico Superior, University of Zaragoza \\ C/ María de Luna, 3 \\ 50018 Zaragoza (Spain)
}

\begin{abstract}
The use of vegetable oils as an energetic supply for transportation and heating purposes is becoming a possible and technically feasible option to reduce the energetic dependence on oil of developed countries. A mathematical model is developed in order to study the combustion of the most common rapeseed oil in heating devices. The study is about the simple model of droplet evaporation and burning, trying to highlight the most relevant physical processes occurring in the environment of the droplet during vaporization and subsequent combustion of rapeseed oil. A comparison with results obtained from the same model but applied to diesel fuel is provided, which allows to establish the most critical aspects affecting rapeseed oil use as a fuel in relation to that of conventional diesel.
\end{abstract}

\section{Key words}

Combustion, rapeseed, oil, droplet, evaporation

\section{Introduction}

Fat and oils have the molecular structure indicated in Figure 1, consisting of three fatty acids chains attached to a glycerol body and resulting in the so-called triglyceride of fatty acids. The saturated or unsaturated hydrocarbon chains R1, R2 or R3 plus the carboxylic group COO compose the whole structure of each fatty acid. These triglycerides make up all kind of fats and oils both from animal and vegetable origin. Excess in oil acidity determines a higher portion of fatty acids dissociated from the triglyceride molecule. Acidity is normally observed in values not greater than $10 \%$ in a volume basis; with acidity rate depending on time elapsed since oil extraction from feedstock. For recently manufactured oils or fats this acidity does not exceed 2 or $3 \%$, which could be considered as the most frequent occurrence.<smiles>[R1]C(=O)OC([2H])C([2H])OC([R2])=O</smiles>

Fig. 1. Molecule of fat or oil [1]

Table 1 shows the chemical structure of the fatty acid chains found in the most common source materials. Except for C3 and C5 compounds, only acids with an even number of carbons occur naturally. Acids may be saturated (containing only single bonds) or unsaturated (containing one or more double bonds). A saturated fat is one that can not chemically add more hydrogen. An unsaturated fat can be hydrogenated; for each degree of unsaturation, i.e., each double bond, two hydrogen atoms can be added per fatty acid.

TABLE 1. - Structural formula for fatty acids composing fats and oils [1]

\begin{tabular}{|c|c|c|}
\hline $\begin{array}{l}\text { Acid } \\
\text { chain }\end{array}$ & $\begin{array}{l}\text { No. of } \\
\text { carbons }\end{array}$ & Structure \\
\hline Caprylic & 8 & $\mathrm{CH}_{3}\left(\mathrm{CH}_{2}\right)_{6} \mathrm{COOH}$ \\
\hline Capric & 10 & $\mathrm{CH}_{3}\left(\mathrm{CH}_{2}\right)_{8} \mathrm{COOH}$ \\
\hline Lauric & 12 & $\mathrm{CH}_{3}\left(\mathrm{CH}_{2}\right)_{10} \mathrm{COOH}$ \\
\hline Myristic & 14 & $\mathrm{CH}_{3}\left(\mathrm{CH}_{2}\right)_{12} \mathrm{COOH}$ \\
\hline Palmitic & 16 & $\mathrm{CH}_{3}\left(\mathrm{CH}_{2}\right)_{14} \mathrm{COOH}$ \\
\hline Palmitoleic & 16 & $\mathrm{CH}_{3}\left(\mathrm{CH}_{2}\right)_{5} \mathrm{CH}=\mathrm{CH}\left(\mathrm{CH}_{2}\right)_{7} \mathrm{COOH}$ \\
\hline Stearic & 18 & $\mathrm{CH}_{3}\left(\mathrm{CH}_{2}\right)_{16} \mathrm{COOH}$ \\
\hline Oleic & 18 & $\mathrm{CH}_{3}\left(\mathrm{CH}_{2}\right)_{7} \mathrm{CH}=\mathrm{CH}\left(\mathrm{CH}_{2}\right)_{7} \mathrm{COOH}$ \\
\hline Linoleic & 18 & $\mathrm{CH}_{3}\left(\mathrm{CH}_{2}\right)_{4} \mathrm{CH}=\mathrm{CHCH}_{2} \mathrm{CH}=\mathrm{CH}\left(\mathrm{CH}_{2}\right)_{7} \mathrm{COOH}$ \\
\hline Linolenic & 18 & $\mathrm{CH}_{3} \mathrm{CH}_{2} \mathrm{CH}=\mathrm{CHCH}_{2} \mathrm{CH}=\mathrm{CHCH}_{2} \mathrm{CH}=\mathrm{CH}\left(\mathrm{CH}_{2}\right), \mathrm{COOH}$ \\
\hline Arachidic & 20 & $\mathrm{CH}_{3}\left(\mathrm{CH}_{2}\right)_{18} \mathrm{COOH}$ \\
\hline Ejcosenoic & 20 & $\mathrm{CH}_{3}\left(\mathrm{CH}_{2}\right)_{7} \mathrm{CH}=\mathrm{CH}\left(\mathrm{CH}_{2}\right)_{4} \mathrm{COOH}$ \\
\hline Behenic & 22 & $\mathrm{CH}_{3}\left(\mathrm{CH}_{2}\right)_{20} \mathrm{COOH}$ \\
\hline Erucic & 22 & $\mathrm{CH}_{3}\left(\mathrm{CH}_{2}\right)_{7} \mathrm{CH}=\mathrm{CH}\left(\mathrm{CH}_{2}\right)_{11} \mathrm{COOH}$ \\
\hline
\end{tabular}


Table 2 [1] summarizes typical fatty acid composition data for triglycerides extracted from different fats and oils. For most feedstocks of interest the majority of the fatty acids have 16 and 18 carbon length chains. For instance, animal tallow is composed of about $60 \%$ saturated, palmitic and stearic acids. The remainder is singly unsaturated oleic acid. Soybean oil, corn oil, peanut oil, etc. contain predominantly unsaturated acids, the majority containing oleic and linoleic acids (doubly unsaturated). Rapeseed oil from some sources contains a high percentage of the monounsaturated C22 erucic acid and C20 eicosenoic. Mononsaturated (oleic), disaturated (linoleic) and trisaturated (linolenic) C18 fatty acids are found as well for rapeseed oil, although in rather lower levels than those registered for the former. Reference [6] gives similar fatty acid compositions, detecting significant portions of erucic, eicosenoic, oleic and linoleic acids.

TABLE 2. - Weight percent of fatty acids in various fat and oils feedstocks [1]

\begin{tabular}{|c|c|c|c|c|c|c|c|c|c|c|c|c|c|}
\hline \multirow{2}{*}{$\begin{array}{l}\text { Carbon } \\
\text { number }\end{array}$} & \multicolumn{7}{|c|}{ Saturated acids } & \multicolumn{4}{|c|}{ Mono unsaturated acids } & \multirow[t]{2}{*}{$\mathrm{Di}$} & \multirow[t]{2}{*}{ Tri } \\
\hline & 8 & 10 & 12 & 14 & 16 & 18 & $>18$ & $<16$ & 16 & 18 & $>18$ & & \\
\hline Beef tallow & - & - & 0.2 & $2-3$ & $25-30$ & $21-26$ & $0.4-1$ & 0.5 & $2-3$ & $39-42$ & 0.3 & 2 & \\
\hline Butter & $1-2$ & $2-3$ & $1-4$ & $8-13$ & $25-32$ & $8-13$ & $0.4-2$ & $1-2$ & $2-5$ & $22-29$ & $0.2-1.5$ & 3 & \\
\hline Coconut & 5-9 & $4-10$ & $44-51$ & $13-18$ & $7-10$ & $1-4$ & - & - & - & $5-8$ & & $1-3$ & \\
\hline Cod liver & - & - & - & $2-6$ & $7-14$ & $0-1$ & & $0-2$ & $10-20$ & $25-31$ & $35-52$ & & \\
\hline Com & - & - & - & $0-2$ & $8-10$ & $1-4$ & & & $1-2$ & $30-50$ & $0-2$ & $34-56$ & \\
\hline Cottonseed & - & - & - & $0-3$ & $17-23$ & $1-3$ & & & & $23-41$ & $2-3$ & $34-55$ & \\
\hline Lard & - & - & - & 1 & $25-30$ & $12-16$ & & 0.2 & $2-5$ & $4|-5|$ & $2-3$ & $4-22$ & \\
\hline Linseed & - & - & - & 0.2 & $5-9$ & $0-1$ & - & - & - & $9-29$ & & $8-29$ & $45-67$ \\
\hline Palm & - & - & - & $1-6$ & $32-47$ & $1-6$ & - & - & - & $40-52$ & & $2-11$ & \\
\hline Palm kernal & $2-4$ & $3-7$ & $45-52$ & $14-19$ & $6-9$ & $1-3$ & $1-2$ & & $0-1$ & $10-18$ & & $1-2$ & \\
\hline Peanut & - & - & - & 0.5 & $6-11$ & $3-6$ & $5-10$ & & $1-2$ & $39-66$ & & $17-38$ & \\
\hline Rapesee & - & - & - & - & $2-5$ & $1-2$ & 0.9 & & 0.2 & $10-15$ & $50-60$ & $10-20$ & $5-10$ \\
\hline Safflower & - & - & - & - & 5.2 & 2.2 & & & & 76.3 & & 16.2 & \\
\hline Soybean & - & - & - & 0.3 & $7-11$ & $3-6$ & $5-10$ & & $0-1$ & $22-34$ & & $50-60$ & $2-10$ \\
\hline Sunflower & & & & & 6.0 & 4.2 & 1.4 & & & 18.7 & & 69.3 & 0.3 \\
\hline Tung & - & - & - & - & - & - & - & - & - & $4-13$ & & $8-15$ & bulk \\
\hline
\end{tabular}

However, when examining scientific literature looking for fatty acid weight distribution data, different and diverging results are compiled, which may indicate different quality degree or even variety or kind of fatty material being analysed.

Regarding the feedstock chosen to be subjected to a combustion study for droplet burning, i.e., refined rapeseed oil, the same apparent lack of reliable thermodynamic data is encountered.. Major authors devoted to research of vegetable fuels for both automotive and heating purposes [2], [3], [4], [5], have published interesting fatty acid distributions for several fatty materials and in particular for rapeseed oil as well. All of them, however, have reported fatty acid weight distribution centred on 18 carbons, instead of the reports from former studies of 20 or 22 carbons [1] [6].

The choice of any of both fatty acid distributions (either 2022 carbons or 18) is conditioned to available thermodynamic data for rapeseed oil, which was almost completely obtained from the work reported in [7]. This paper provides molecular weight $\mathrm{MW}_{\mathrm{F}}$ and $\mathrm{H}: \mathrm{C}$ ratio for rapeseed oil, thereby permitting to determine its elemental composition and finally its chemical formula as well:

$$
\begin{aligned}
& M W_{F}=926 \mathrm{~kg} / \mathrm{kmol} \\
& \mathrm{H}: \text { C ratio }=1.81
\end{aligned}
$$

Assuming this data, the structural formula $\mathrm{C}_{\mathrm{x}} \mathrm{H}_{\mathrm{y}} \mathrm{O}_{6}$ of rapeseed oil can be determined by solving a two-equations system in unknowns $x$ and $y$. The result is

$$
\mathrm{C}_{60} \mathrm{H}_{108.6} \mathrm{O}_{6}
$$

By taking away the three carbon atoms belonging to glycerol, the remaining 57 carbon atoms are to be distributed within the three fatty acid chains including the carboxylic group. Hence, several combinations of different fatty acids (of 18, 20, 22 and some of 16 carbons) can be attached to glycerol main body, thus resulting in total consistency between the above formula and the weight percent distribution for fatty acids referred at the beginning of this introduction [1]-[6].

There exists also the possibility of filtering and refining from rapeseed oil those fractions of triglycerides composed only by a specific kind of fatty acids. Following this idea, the chemical formula for oleic-acid triglyceride could be perfectly represented by $\mathrm{C}_{57} \mathrm{H}_{104} \mathrm{O}_{6}$, and consequently elemental composition set as integer numbers. Nevertheless, this separation process results for heating purposes very expensive and economically unfeasible because use of distillation would increase final price of fuel. In any case, either distilled or not, rape oil burning difficulties remain as a major problem, so that combustion improvement continues to be the sole way to improve burning of vegetable oils after a first refining.

The assumption of formula (3) for rapeseed oil leads to consider this feedstock to be a liquid consisting of one component only. The application of the single component postulate in this case is most justified by the physical nature of the problem (being really a mixture of triglicerides of several acids), but by the fact that it leads to considerable simplification of the model.

In case of multicomponent fuels, Reference [8] states that different component obviously evaporate at different rates, creating concentration gradients in the liquid phase and thus different thermal behaviours or each substance. Then, the evaporation rate of the $i$ th species can be presented as:

$$
\begin{aligned}
& m_{i}=\varepsilon_{i} m_{d} \\
& \varepsilon_{i}=Y_{i, S}
\end{aligned}
$$

where $\varepsilon_{i}$ describes the mass fraction of species $i$ th on droplet surface and $\dot{m}_{d}$ indicates the evaporation rate of 
the whole fuel droplet. In addition, it should be indicated that equation (5) is only valid if there is no diffusion of the $i$ th species from the interior of droplet to the surface, i.e., the sole contribution of vaporized matter from droplet to flow must be that due to evaporation on the surface.

Table 3 is a compilation of thermodynamic data of rapeseed oil provided by [7], [6] and [4]. This data is the base of the calculations undertaken in this paper.

TABLE 3. - Thermodynamic properties of rapeseed oil

\begin{tabular}{lcc}
\hline \multicolumn{1}{c}{ PROPERTY } & $\mathrm{UNIT}$ & \\
\hline Enthalpy of combustion $\Delta h_{c}(298 \mathrm{~K})$ & {$[\mathrm{kJ} / \mathrm{kg}]$} & 40200 \\
$H H V$ & & \\
Enthalpy of combustion $\Delta h_{c}(298 \mathrm{~K}) L H V$ & {$[\mathrm{~kJ} / \mathrm{kg}]$} & 37620 \\
Enthalpy of vaporization $h_{f g}\left(T_{\text {boil }}\right)$ & {$[\mathrm{kJ} / \mathrm{kg}]$} & 209 \\
H:C Ratio & {$[-]$} & 1.81 \\
O:C Ratio & {$[-]$} & 0.096 \\
Molecular weight $M W_{F}$ & {$[\mathrm{~kg} / \mathrm{kmol}]$} & 926 \\
Flash point $T_{f l a s h}$ & {$[\mathrm{~K}]$} & 546 \\
Critical point $T_{c}$ & {$[\mathrm{~K}]$} & 765 \\
Boiling point $T_{\text {boil }}$ & {$[\mathrm{K}]$} & 584 \\
Density $\rho$ (373 K) & {$\left[\mathrm{kg} / \mathrm{m}^{3}\right]$} & 778 \\
Temperature derivative $d \rho / d T(373 \mathrm{~K})$ & {$\left[\mathrm{kg} / \mathrm{m}^{3} \cdot \mathrm{K}\right]$} & -0.64 \\
Constant-P specific heat $C_{p}(373 \mathrm{~K})$ & {$[\mathrm{kJ} / \mathrm{kg} \cdot \mathrm{K}]$} & 2.43 \\
Temperature derivative $d C_{p} / d T(373 \mathrm{~K})$ & {$\left[\mathrm{kJ} / \mathrm{kg} \cdot \mathrm{K}^{2}\right]$} & 0.00411 \\
Thermal conductivity $k(373 \mathrm{~K})$ & {$\left[\mathrm{W} / \mathrm{m}^{\prime} \cdot \mathrm{K}\right]$} & 0.15 \\
Temperature derivative $d k / d T(373 \mathrm{~K})$ & {$\left[\mathrm{W} / \mathrm{m}^{2} \cdot \mathrm{K}^{2}\right]$} & -0.00011 \\
Kinematic viscosity $v(313 \mathrm{~K})$ & {$[\mathrm{mm} / \mathrm{s}]$} & 46.68 \\
Kinematic viscosity $v(373 \mathrm{~K})$ & {$[\mathrm{mm} / \mathrm{s}]$} & 9.35 \\
Vapour pressure $P_{v}(373 \mathrm{~K})$ & {$[\mathrm{Pa}]$} & $3.72 \cdot 10^{-9}$ \\
\hline
\end{tabular}

The above data is used to specify a simple model of droplet burning, as a fist step to gain understanding of the physical phenomena of rapeseed oil combustion. We follow the classical treatment, as summarized for instance in [9].

\section{Simple model of droplet burning}

In this section the evaporation and burning of spherical liquid droplets as nonpremixed combustion process is considered and analysed for the case of rapeseed oil. Finding analytic solutions to the governing conservation equations is the way to better understand the burning process of a droplet.

\begin{tabular}{|ll|}
\hline NOMENCLATURE \\
$a$ & Molar oxidizer-fuel ratio [kmol/kmol] \\
$A$ & Clausius-Clapeyron integration constant $[\mathrm{Pa}]$ \\
$B$ & Clausius-Clapeyron integration constant $[\mathrm{K}]$ \\
$c_{p g}$ & Gas-phase specific heat $[\mathrm{kJ} / \mathrm{kg} \cdot \mathrm{K}]$ \\
$c_{p l}$ & Liquid-phase specific heat $[\mathrm{kJ} / \mathrm{kg} \cdot \mathrm{K}]$ \\
\hline
\end{tabular}

\begin{tabular}{|c|c|}
\hline$D$ & Mass diffusivity $\left[\mathrm{m}^{2}\right]$ \\
\hline$\Delta h_{c}^{L H V}$ & Enthalpy of combustion LHV [kJ/kg] \\
\hline$H H V$ & Higher heating value \\
\hline$h_{f g}$ & Latent heat of vaporization $[\mathrm{kJ} / \mathrm{kg}]$ \\
\hline$k_{g}$ & Gas-phase thermal conductivity $[\mathrm{kW} / \mathrm{m} \cdot \mathrm{K}]$ \\
\hline Le & Lewis number \\
\hline$L H V$ & Lower heating value \\
\hline$\dot{m}_{F}$ & Droplet mass burning rate $[\mathrm{kg} / \mathrm{s}]$ \\
\hline$m_{F}$ & Fuel mass $[\mathrm{kg}]$ \\
\hline$m_{O x}$ & Oxidizer [kg] \\
\hline$M W_{F}$ & Fuel molecular weight $[\mathrm{kg} / \mathrm{kmol}]$ \\
\hline$M W_{\text {Air }}$ & Air molecular weight $[\mathrm{kg} / \mathrm{kmol}]$ \\
\hline$M W_{P r}$ & Products molecular weight $[\mathrm{kg} / \mathrm{kmol}]$ \\
\hline$P$ & Pressure $[\mathrm{Pa}]$ \\
\hline$r_{S}$ & Radial coordinate at surface [m] \\
\hline$r_{f}$ & Radial coordinate at flame sheet [m] \\
\hline$R_{u}$ & Universal gas constant $[8.31451 \mathrm{~kJ} / \mathrm{kmol} \cdot \mathrm{K}]$ \\
\hline$T_{o}$ & Liquid fuel temperature at inlet [K] \\
\hline$T_{s}$ & Droplet surface temperature [K] \\
\hline$T_{\text {boil }}$ & Fuel boiling temperature [K] \\
\hline$T_{f}$ & Flame temperature $[\mathrm{K}]$ \\
\hline$T_{\infty}$ & Temperature at infinity $[\mathrm{K}]$ \\
\hline $\bar{T}$ & Average temperature $[\mathrm{K}]$ \\
\hline$x$ & Number of carbon atoms in fuel \\
\hline$X_{F}$ & Fuel molar fraction \\
\hline$y$ & Number of hydrogen atoms in fuel \\
\hline$Y_{F, s}$ & Fuel vapour mass fraction at the droplet surface \\
\hline$Y_{F}$ & Fuel vapour mass fraction \\
\hline$Y_{P r}$ & Products mass fraction \\
\hline$Y_{O x}$ & Oxidizer mass fraction \\
\hline$z$ & Number of oxygen atoms in fuel \\
\hline$v$ & Oxidizer-fuel stoichiometric ratio $[\mathrm{kg} / \mathrm{kg}]$ \\
\hline$\rho$ & Density $\left[\mathrm{kg} / \mathrm{m}^{3}\right]$ \\
\hline
\end{tabular}

The simple model of the droplet burning lies in assuming a spherically symmetric quasi-steady diffusion flame that surrounds the droplet within a quiescent infinite environment characterised by having no convection phenomena nor interaction with any other structure. Droplet temperature is assumed to be the inlet temperature of liquid oil within the inner region of the droplet, apart from a thin outer surface layer, where temperature is higher as a result of the heating from the droplet environment (“onion skin" model). 
As reported in the introduction, rapeseed oil fuel is treated as a single component liquid (no soot or liquid water) with zero solubility for gases. Furthermore, phase equilibrium prevails at the liquid-vapour interface. On the other hand, fuel and oxidizer react in stoichiometric proportions whereas chemical kinetics is assumed to be infinitely fast, allowing the flame to be represented as an infinitesimally thin sheet. The characteristic Lewis number of rapeseed oil $L e=k_{g} / \rho c_{p g} D$ is approximately set to unity, which results in a great simplification. The vapour thermal conductivity $k_{g}$, the specific heat $c_{p g}$ and the product of the density and mass diffusivity $\rho D$ are all constants. The pressure surrounding the droplet is considered to be constant and uniform, while radiation heat transfer is assumed negligible.

Gas phase consists of only three species: rapeseed oil vapour, oxidizer and combustion products. The gas phase region is divided into two zones. The inner zone between the droplet surface $\left(r_{S}\right)$ and the flame sheet $\left(r_{f}\right)$ contains only fuel vapour and products; the outer zone, beyond the flame, contains products and oxidizer, but no trace of fuel. This allows of course a simple model of binary diffusion. Figure 2 shows the species concentration in both regions. Also shown is the temperature profile, introducing three important magnitudes: the droplet surface temperature $T_{S}$, the flame temperature $T_{f}$ (being the highest because of completion of fuel combustion) and the temperature of the medium at the infinity $T_{\infty}$. The fuel mass fraction, $Y_{F}$, is a maximum at the droplet surface and monotonically decreases to zero at the flame, where the flame is totally consumed. The combustion products $\left(Y_{P_{r}}\right)$ have their maximum concentration at the flame sheet, diffusing toward the droplet and outward away from the flame. The oxidizer mass fraction $Y_{O x}$ is zero at the flame sheet and increases monotonically toward infinity, where there is maximum (unity).
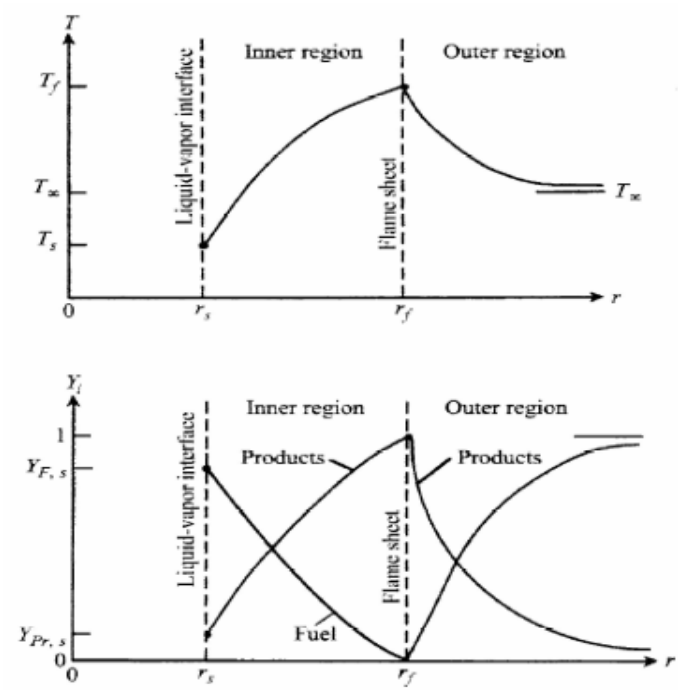

Fig. 2. Temperature and species profile for simple droplet burning [9]
The aim of this study is to solve for some variables that describe the physics of the droplet burning. These unknowns are obtained from the governing conservation equations and allow to assess the most relevant parameters involved in the evaporation and subsequent burning of the rapeseed oil droplet; namely the droplet mass burning rate $\dot{m}_{F}$, the fuel mass fraction $Y_{F, s}$, the temperatures at each crucial area and the position of flame sheet $r_{f}$. These solutions enable to explore the influence of droplet size and ambient conditions on both droplet evaporation and burning times.

The following five equations are the result of the five conservation principles cited next [9]: the oxidizer species conservation in the outer region (6), the energy balance at droplet liquid-vapour interface (7), the energy balance at flame sheet (8), the fuel species conservation in the inner region (9) and the liquid-vapour phase equilibrium at interface with Clausius-Clapeyron equation (10).

\section{Summarizing,}

$$
\begin{aligned}
& \dot{m}_{F}=\frac{4 \pi k_{g} r_{s}}{c_{p g}} \ln \left[1+B_{o, q}\right] \\
& T_{f}=\frac{c_{p l}\left(T_{s}-T_{o}\right)+h_{f g}\left[v B_{o, q}-1\right]+T_{s}}{c_{p g}(1+v)} \\
& r_{f}=r_{s} \frac{\ln \left[1+B_{o, q}\right\rfloor}{\ln [(1+v) / v]} \\
& Y_{F, s}=\frac{B_{o, q}-1 / v}{B_{o, q}+1}-B_{P} \\
& T_{s}=\frac{-M W_{P r} Y_{F, s} P}{\ln \left[\frac{\left.M W_{F}-Y_{F, s} M W_{P r}-M W_{F}\right)}{A\left(Y_{F, s} M W\right.}\right]}
\end{aligned}
$$

Being $B_{o, q}$ the transfer number:

$$
B_{o, q}=\left[\frac{\Delta h_{c}^{L H V} / v+c_{p g}\left(T_{\infty}-T_{s}\right)}{c_{p l}\left(T_{s}-T_{o}\right)+h_{f g}}\right]
$$

and $A$ and $B$ the constants of the general solution $P=A \cdot \exp (-$ $B / T$ ) obtained from the Clausius-Clapeyron equation in this case:

$$
A=1.013 \cdot 10^{5} \exp \left(\frac{h_{f g} M W_{F}}{R_{u} T_{b o i l}}\right)
$$




$$
B=\left(\frac{h_{f g} M W_{F}}{R_{u}}\right)
$$

Another less formal possibility for determining the parameters $A$ and $B$ is to set the Clausius-Clapeyron general solution to the vapour pressure and corresponding temperature values defined by two single known states for rapeseed oil; specifically, the values of vapour pressure $P_{v}$ at $373 \mathrm{~K}$ and the atmospheric pressure at the boiling temperature $584 \mathrm{~K}$ both derived from data provided in Table 3. Solving the two-equation system for both unknowns $A$ and $B$ facilitates incorporation of these values in the originally formulated Eq. (10).

\section{A. Physical parameters and properties}

Before solving the system of Eqs. (6-10), some physical parameters have to be identified and subsequently set to their appropriate values in order to be able to proceed with a suitable equation solver. The detail is as follows.

\section{1) Combustion parameters}

Firstly, the stoichiometric combustion reaction of any oxygenated hydrocarbon fuel can be expressed as

$$
\begin{aligned}
& \mathrm{C}_{x} \mathrm{H}_{y} \mathrm{O}_{z}+a\left(\mathrm{O}_{2}+3.76 \mathrm{~N}_{2}\right) \rightarrow x \mathrm{CO}_{2}+\frac{y}{2} \mathrm{CO}_{2}+a \cdot 3.76 \mathrm{~N}_{2} \\
& a=x-\frac{z}{2}+\frac{y}{4}
\end{aligned}
$$

At the flame sheet, the oxidizer and fuel combine in stoichiometric proportions according to:

$$
\begin{aligned}
& 1 \mathrm{~kg} \text { Fuel }+v \mathrm{~kg} \text { Oxidizer }=(\boldsymbol{V}+1) \mathrm{kg} \text { Products } \\
& v=\frac{m_{O x}}{m_{F}}=\frac{4.76 a M W_{\text {Air }}}{M W_{F}}
\end{aligned}
$$

where the stoichiometric oxidizer-fuel ratio includes any non-reacting gases (e.g. $\mathrm{N}_{2}$ ) as part of the oxidizer stream (air). Taking the mean value of $M W_{\text {Air }}$ to be $28.85 \mathrm{~kg} / \mathrm{kmol}$ [9] and the other parameters from Table 3 and Eq. (3), the value of the air-fuel stoichiometric ratio is calculated as $v=12.45$. This means that the air mass is more than twelve times the fuel mass; simply a little lesser quantity than the ratio observed for other fuels containing no oxygen $(\sim 16)$. The presence of six oxygen atoms in rapeseed oil does facilitate combustion through an significant reduction of air consumption.

\section{2) Specific heat of gas phase}

The gas phase consists of a mixture of fuel vapour and combustion products for the inner region and combustion products and oxidizer for the outer region. This variety of species along the radial position makes difficult to find out a value of the their specific heat. Since the model, Eqs. (6)(13), involves a constant value of $c_{p g}$, an adequate average must be assigned, also taking into account that temperature is variable.

On the one hand, temperature at the droplet surface will be a few kelvins below the boiling point, i.e. about $550 \mathrm{~K}$, which means that the molar fraction of rapeseed oil vapour is roughly $\mathrm{X}_{\mathrm{F}, \mathrm{s}}=\mathrm{P}_{\mathrm{v}}^{550} / \mathrm{P}_{\mathrm{atm}} \sim 0.085$, indeed a very low proportion compared to that of combustion products. However, due to the great difference in molar masses, this translates in a mass fraction $\mathrm{Y}_{\mathrm{F}, \mathrm{s}} \sim 0.75$, so that no easy approximation can be envisaged.

On the other hand, as observed in Figure 2, the mass fraction of products and oxidized are unity at the flame sheet and infinity, respectively. Furthermore, no piece of information was found for the specific heat of gas-phase rapeseed oil, whereas data of both products and oxidizer are easily available in any appropriate thermodynamic database.

It is recommended to use the specific heat of the combustion products $c_{p}{ }^{P r}$ as the necessary parameter to give closure to the problem instead of that of air (gas at infinity). This assumption will result in a temperature profile at the flame sheet determined with high degree of accuracy, due to the massive presence of products within this area; being the profile at infinity and at the droplet surface more approximate. As an attenuating aspect, it is important to highlight that the values of specific heat for products and air are quite similar all along the temperature range registered in the problem, thus $c_{p}{ }^{P r}$ being a good approximation even for the outer region at infinity.

The calculation of $c_{p g}$ is carried out for products at the average temperature of flame sheet and droplet surface [9]:

$$
\begin{aligned}
& T=\frac{T_{s}+T_{f}}{2}=\frac{549 \mathrm{~K}+2331 \mathrm{~K}}{2} \approx 1440 \mathrm{~K} \\
& c_{p g} \approx c_{p}^{\operatorname{Pr}}=\sum_{i} Y_{i} c_{p, i}^{\operatorname{Pr}}(T)
\end{aligned}
$$

\section{3) Bulk temperature at infinity}

The fuel droplet is assumed to be burning in a quiescent environment at ambient temperature $T_{\infty}=300 \mathrm{~K}$ as an isolated punctual mass of rapeseed oil. A group of droplets in combustion in the same portion of space will increase the temperature of the whole area as the sum of contributions of all droplets. 


\section{4) Specific heat of liquid phase}

According to the "onion skin" model explained above, the fuel droplet is made of a main body at ambient temperature $T_{o}$ and a thin layer on the surface at $T_{s} \sim 549 \mathrm{~K}$. Due to the lack of data of liquid specific heat through all the temperature range, and taking into account from the data shown in Table 3, an approximated expression for any temperature can be built in order to assess this parameter.

$$
\begin{aligned}
& \left.c_{p l} \approx c_{p l}\right|_{373}+\left.\frac{d c_{p l}}{d T}\right|_{373} \cdot(T-373) \\
& \left.c_{p l}\right|_{425} \approx 2.642 \mathrm{~kJ} / \mathrm{kg} \cdot \mathrm{K}
\end{aligned}
$$

To get a constant value for the model, the average temperature $\mathrm{T}=(300 \mathrm{~K}+549 \mathrm{~K}) / 2 \sim 425 \mathrm{~K}$ is considered.

\section{5) Thermal conductivity}

Table 3 provides rapeseed oil thermal conductivity only at $373 \mathrm{~K}$. The corresponding value at $T \approx 1440 \mathrm{~K}$ is e calculated through the approximation suggested by Law and Williams [9]:

$$
k_{g}=0.4 k_{F}(T)+0.6 k_{O x}(T)
$$

where the subscripts $F$ represent the fuel vapour and Ox the air. The parameter $k_{O x}$ is found in tables of transport properties [9], whereas that for fuel vapour is estimated by using a $\mathrm{T}^{1 / 2}$-dependence (23) to extrapolate from $373 \mathrm{~K}$ to $1440 \mathrm{~K}$.

$$
k \propto T^{1 / 2}
$$

Thus,

$$
k_{F}(T)=k_{F}(373) \cdot\left[\frac{T}{373}\right]^{1 / 2}
$$

and the gas thermal conductivity results in:

$$
k_{g}=169 \cdot 10^{-6} \mathrm{~kW} / \mathrm{m} \cdot \mathrm{K}
$$

Another possibility is to adopt data of Table 3 for the temperature derivative of thermal conductivity. A expression similar to Eq. (20) can be built in this way, although accuracy is lower than that of the $\mathrm{T}^{1 / 2}$ approach.

\section{6) Liquid density}

Following the scheme exposed for the specific heat of the liquid phase, liquid density can be evaluated at the average temperature $\mathrm{T}=(300 \mathrm{~K}+549 \mathrm{~K}) / 2 \sim 425 \mathrm{~K}$ from data in Table 3:

$$
\left.\rho_{l} \approx \rho_{l}\right|_{373}+\left.\frac{d \rho_{l}}{d T}\right|_{373} \cdot(T-373)
$$

$$
\left.\rho_{l}\right|_{425} \approx 745 \mathrm{~kg} / \mathrm{m}^{3}
$$

Table 4 summarizes the values of all the parameters needed for the calculation, as estimated by the procedures just explained.

TABLE 4. - Numerical values for involved parameters

\begin{tabular}{lcc}
\hline PARAMETER & $\mathrm{UNIT}$ & \\
\hline$a$ & {$[\mathrm{kmol} / \mathrm{kmol}]$} & 84.15 \\
$c_{p g}$ & {$[\mathrm{~kJ} / \mathrm{kg} \cdot \mathrm{K}]$} & 1.358 \\
$c_{p l}{ }^{L}$ & {$[\mathrm{~kJ} / \mathrm{kg} \cdot \mathrm{K}]$} & 2.642 \\
$\Delta h_{c}{ }^{L H V}$ & {$[\mathrm{~kJ} / \mathrm{kg}]$} & 37620 \\
$h_{f g}$ & {$[\mathrm{~kJ} / \mathrm{kg}]$} & 209 \\
$k_{g}$ & {$[\mathrm{~kW} / \mathrm{m} \cdot \mathrm{K}]$} & $169 \cdot 10^{-6}$ \\
$M W_{F}$ & {$[\mathrm{~kg} / \mathrm{kmol}]$} & 926 \\
$M W_{A i r}$ & {$[\mathrm{~kg} / \mathrm{kmol}]$} & 28.85 \\
$M W_{P r}$ & {$[\mathrm{~kg} / \mathrm{kmol}]$} & 28.98 \\
$P$ & {$[\mathrm{~Pa}]$} & $1.013 \cdot 10^{5}$ \\
$r_{S}$ & {$[\mathrm{~m}]$} & $100 \cdot 10^{-6}$ \\
$R_{u}$ & {$[\mathrm{~kJ} / \mathrm{kmol} \cdot \mathrm{K}]$} & 8.31451 \\
$T_{o}$ & {$[\mathrm{~K}]$} & 300 \\
$T_{b o i l}$ & {$[\mathrm{~K}]$} & 584 \\
$T_{\infty}$ & {$[\mathrm{K}]$} & 300 \\
$x$ & {$[-]$} & 60 \\
$y$ & {$[-]$} & 108.6 \\
$z$ & {$[-]$} & 6 \\
$v$ & {$[\mathrm{~kg} / \mathrm{kg}]$} & 12.45 \\
$\rho_{l}$ & {$\left[\mathrm{~kg} / \mathrm{m}^{3}\right]$} & 745 \\
\hline
\end{tabular}

\section{Problem solution and results}

The system given by Eqs. (6)-(10) is solved for the five unknowns previously mentioned, namely, $\dot{m}_{F}, r_{f}, T_{f}, T_{S}$, $Y_{F, s}$, by means of a commercial numerical solver [11]. The program is specialized in thermal and chemical calculations, thus incorporating adequate databases for properties such as molecular weights and properties of pure substances. Table 5 shows sample results of the calculation, for a specific initial radius of the droplet.

The model also allows some derived calculations of interest. For instance, droplet lifetime, i.e. the time that takes a droplet of given initial size to evaporate and burn completely, can be easily deduced from mass transfer considerations as

$$
t_{d}=\frac{\left(2 r_{s}\right)^{2}}{\frac{8 k_{g}}{\rho_{l} c_{p g}} \ln \left(1+B_{o, q}\right)}
$$

Table 5 shows the values of the five unknowns, which have been main object of this analysis. 
TABLE 5. - Results for $r_{s}=100 \mu \mathrm{m}$

\begin{tabular}{lcc}
\hline UNKNOWN & UNIT & \\
\hline$\dot{m}_{F}$ & {$[\mathrm{~kg} / \mathrm{s}]$} & $2.203 \cdot 10^{-7}$ \\
$r_{f}$ & {$[\mathrm{~m}]$} & 0.001824 \\
$T_{f}$ & {$[\mathrm{~K}]$} & 2331 \\
$T_{S}$ & {$[\mathrm{~K}]$} & 549.2 \\
$Y_{F, s}$ & {$[\mathrm{~kg} / \mathrm{kg}]$} & 0.7361 \\
\hline
\end{tabular}

Table 6 includes the droplet lifetime associated to different values of $r_{s}$ (droplet size). The quadratic dependence is represented in Figure 3. In contrast, $r_{f}$ and $m_{F}$ exhibit a lineal dependence on droplet radius, as easily deduced from algebra of Eqs. (6)-(8).

TABLE 6. - Parametric table of physical variables for different values of $r_{s}$ [ $\left.\mu \mathrm{m}\right]$

\begin{tabular}{cccc}
\hline $\begin{array}{c}r_{s} \\
{[\mu \mathrm{m}]}\end{array}$ & $\begin{array}{c}t_{d} \\
{[\mathrm{~s}]}\end{array}$ & $\begin{array}{c}r_{f} \\
{[\mu \mathrm{m}]}\end{array}$ & $\begin{array}{c}\dot{m}_{F} \\
{[\mathrm{~g} / \mathrm{s}]}\end{array}$ \\
\hline 10 & 0.0002125 & 182.4 & $0.2203 \cdot 10^{-4}$ \\
30 & 0.001913 & 547.2 & $0.6608 \cdot 10^{-4}$ \\
50 & 0.005313 & 912.1 & $1.101 \cdot 10^{-4}$ \\
80 & 0.0136 & 1459 & $1.762 \cdot 10^{-4}$ \\
100 & 0.02125 & 1824 & $2.203 \mathrm{E} \cdot 10^{-4}$ \\
150 & 0.04782 & 2736 & $3.304 \cdot 10^{-4}$ \\
200 & 0.08501 & 3648 & $4.405 \cdot 10^{-4}$ \\
\hline
\end{tabular}

However, both variables $r_{f}$ and $\dot{m}_{F}$ register a linear dependence on droplet radius as easily deduced from algebra of Eqs. (6,8).

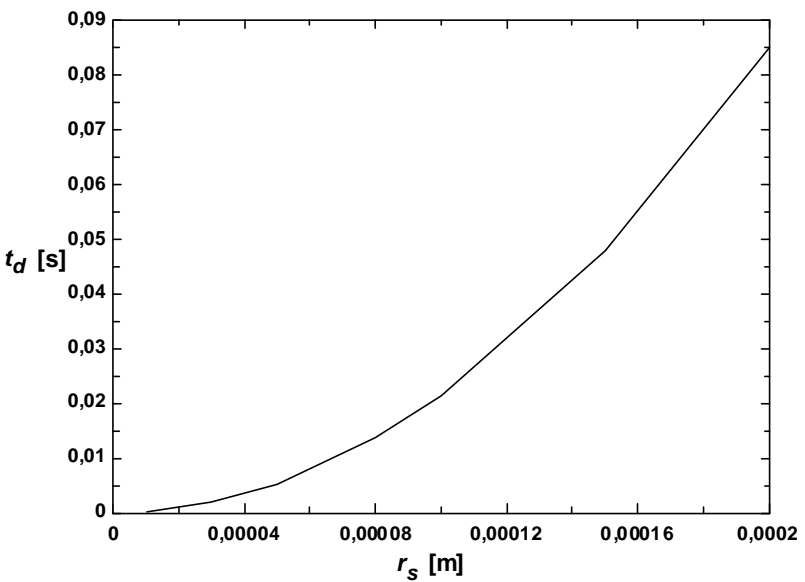

Fig. 3. Droplet lifetime as a function of droplet size

\section{A. Comparison with diesel fuel}

Making a compilation of all the valid parameters for the burning of a droplet of rapeseed oil is a prelude to a work of comparison with the combustible to which this natural oil is called to replace: diesel fuel. Table 7 regroups all these variables with full physic sense from the whole analysis accomplished before.

TABLE 7. - Physical parameters for rapeseed oil $\left(r_{s}=100 \mu \mathrm{m}\right)$

\begin{tabular}{lcc}
\hline UNKNOWN & UNIT & \\
\hline$\dot{m}_{F}$ & {$[\mathrm{~kg} / \mathrm{s}]$} & $4.485 \cdot 10^{-8}$ \\
$t_{d}$ & {$[\mathrm{~s}]$} & 0,1044 \\
$r_{f}$ & {$[\mathrm{~m}]$} & $1824 \cdot 10^{-6}$ \\
$T_{f}$ & {$[\mathrm{~K}]$} & 2331 \\
$T_{S}$ & {$[\mathrm{~K}]$} & 545.9 \\
$Y_{F, s}$ & {$[\mathrm{~kg} / \mathrm{kg}]$} & 0.6786 \\
\hline
\end{tabular}

The same calculations have been repeated for diesel fuel, aimed at the comparison of results. Tables 7 and 8 show the sample results used for the comparison.

TABLE 8. - Model results for diesel fuel $\left(r_{s}=100 \mu \mathrm{m}\right)$

\begin{tabular}{lcc}
\hline \multicolumn{1}{c}{ UNKNOWN } & UNIT & \\
\hline$\dot{m}_{F}$ & {$[\mathrm{~kg} / \mathrm{s}]$} & $6.632 \cdot 10^{-8}$ \\
$t_{d}$ & {$[\mathrm{~s}]$} & 0,06969 \\
$r_{f}$ & {$[\mathrm{~m}]$} & $2653 \cdot 10^{-6}$ \\
$T_{f}$ & {$[\mathrm{~K}]$} & 2383 \\
$T_{S}$ & {$[\mathrm{~K}]$} & 471.5 \\
$Y_{F, s}$ & {$[\mathrm{~kg} / \mathrm{kg}]$} & 0.8046 \\
\hline
\end{tabular}

\section{Conclusions}

As expected for a fuel like diesel, more volatile than rapeseed oil, diesel fuel mass rate is somewhat larger than that of vegetable oil for an equal droplet size; thereby contributing to facilitate its evaporation and subsequent burning. As a consequence, the droplet lifetime is noticeably shorter than that of rapeseed oil; aspect that will certainly condition some criteria used for converting diesel devices into "bio-oil" use. Higher volatility of diesel fuel is logically translated into higher mass fractions at droplet surface as well. Both the flame sheet position and its temperature are to a great extent larger for diesel in relation to those of the biocombustible. This question emphasizes the higher heating value of diesel fuel and the requirement of flame sheet to be as far as possible from droplet surface for maintaining the surface temperature as low as physically acceptable.

\section{References}

[1] M.S. Graboski, R.L. McCormick. Combustión of fat and vegetable oil derived fuels in diesel engines. Prog. Energy Combust. Sci. Vol. 24, 125-164. Elsevier (1998) 
[2] M. Senthil Kumar, A. Ramesh, B. Nagalingam. An experimental comparison of methods to use methanol and Jatropha oil in a compression ignition engine. Biomass and Bioenergy. Vol. 25, 309-318 Elsevier (2003)

[3] A. Fröhlich, B. Rice. Evaluation of Camelina sativa oil as a feedstock for biodiesel production. Industrial Crops and Products. Vol. 21, 25-31 (2005)

[4] R. Altin , S. Çetinkaya, H. Serdar Yücesu. The potential of using vegetable oil fuels as fuel for diesel engines. Energy Conversion and Management. Vol.42, 529-538 (2001)

[5] A.S. Ramadhas, C. Muraleedharan, S. Jayaraj. Performance and emission evaluation of a diesel engine fueled with methyl esters of rubber seed oil. Renewable Energy. Vol. 30, 1789-1800 (2005)

[6] D.L. Reece, C.L. Peterson. A report on the Idaho onroad vehicle test with RME and neat rapeseed oil as an alternative to diesel fuel. ASAE paper, no. 93-5018. ASAE, St. Joseph, MI (1993)

[7] L. Vander Griend, M. Feldman, C.L. Peterson, Properties of rape oil and its methyl ester relevant to combustion modelling. ASAE paper, no. 88-6507. ASAE, St. Joseph, MI (1988)
[8] S.S. Sazhin. Advanced models of fuel droplets heating and evaporation. Progress in energy and combustion science. Vol. 32, 162-214 (2006)

[9] S.R. Turns. An introduction to combustion. Concepts and applications. McGraw-Hill International Editions. Second edition (2000)

[10] S. Chirachakhrit, U. Keochung, J. Tiansuwan. Combustion of blends between plant oils and diesel oil. Renewable energy. Vol. 16, 1098-1101 (1999)

[11] Engineering Equation Solver (EES). F-Chart software. 